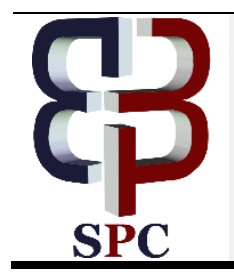

\title{
Molecular structure, NBO analysis, first hyper polarizability, and homo-lumo studies of $\pi$-extended tetrathiafulvalene (EXTTF) derivatives connected to $\pi$-nitro phenyl by density functional method
}

\author{
Tahar Abbaz ${ }^{1 *}$, Amel Bendjeddou ${ }^{1}$, Didier Villemin ${ }^{2}$ \\ ${ }^{1}$ Laboratory of Aquatic and Terrestrial Ecosystems, Org. and Bioorg. Chem. Group, University of Mohamed Che- \\ rif Messaadia, Souk Ahras, 41000, Algeria \\ ${ }^{2}$ Laboratory of Molecular and Thio-Organic Chemistry, UMR CNRS 6507, INC3M, FR 3038, Labex EMC3, ensicaen \& \\ University of Caen, Caen 14050, France \\ *Corresponding author E-mail: tahar.abbaz@univ-soukahras.dz
}

\begin{abstract}
In these study we have been obtained the structural properties of (exTTF) derivatives 1-4 by using B3LYP/6-31G(d,p) of Density Functional Theory (DFT) utilizing Becke three exchange functional and Lee Yang Paar correlation functional. The calculation of first hyperpolarizability shows that the molecules are attractive molecules for future applications in non-linear optics. Molecular electrostatic potential (MEP) at a point in the space around a molecule gives an indication of the net electrostatic effect produced at that point by the total charge distribution of the molecule. The calculated HOMO and LUMO energies show that charge transfer occurs within these molecules.
\end{abstract}

Keywords: Computational Chemistry; Density Functional Theory; Electronic Structure; Quantum Chemical Calculations; Tetrathiafulvalenes.

\section{Introduction}

TTF and its derivatives are strong electron donors. Various electron acceptors have been connected to TTF to afford electron donor-acceptor dyads or triads for investigations of charge transfer interactions and building molecular level devices, such as molecular rectifier and molecular switches (Giacalone F et al. 2004).

In order to develop new materials with stronger interaction, a large number of researches for the synthesis of TTF derivatives possessing a direct coordination site to paramagnetic metal ions and their corresponding metal complexes have been conducted (Lorcy D et al. 2009).

During the past few years, a considerable research effort has been focused upon the synthesis of more sophisticated tetrathiafulvalenes (Khodorkovsky V et al. 1994). In this regard, the preparation of extended $\pi$-donors in which the two dithiole rings are separated by a conjugated spacer have recently received particular attention as a consequence of their potential interest in the preparation of materials with increased dimensionality (Bryce MR. 1995), nonlinear optical properties, (Jen AK et al. 1994) or as small-gap semiconductors (Brisset $\mathrm{H}$ et al. 1994). Donor systems with extended $\pi$-conjugation additionally present a lowering of the oxidation potential due to charge delocalization and a decrease of the Coulombic repulsion in the dication state. This is important in the strategy for the molecular design of novel donor $\pi$-systems (Khodorkovsky $\mathrm{V}$ et al. 1994; Bryce MR. 1995; Jen AK et al. 1994; Brisset H et al. 1994; Takahashi K et al. 1995).
Density functional theory (DFT) is a powerful, formally exact reformulation of quantum mechanics (Hohenberg P et al. 1964; Kohn W et al. 1999; Kohn W et al. 1965). It is distinct from quantum chemical methods because in its revolutionary perspective the electronic density, rather than the many-electron wave function, plays the central role.

In the present investigation, we have presented a complete description of all the available measurement theoretical (exTTF) derivatives 1-4 of described in literature (Otero $\mathrm{M}$ et al. 2002). All this measurements theoretical such as optimized structural parameters, natural bond orbital (NBO) analysis, nonlinear optical (NLO) properties, molecular electrostatic potential and global reactivity descriptors are obtained using the Density Functional Theory (DFT), performing B3LYP/6-31G(d,p) level of calculations.

\section{Materials and methods}

All the quantum chemical calculations have been carried out with Gaussian 09 program package (Frisch MJ et al. 2009) using DFT method, B3LYP functional and 6-31G (dip) basis set to predict the molecular structure, electronic transitions, electronic reactivity descriptors and first hyperpolarizability. B3LYP invokes Becke's three parameter (local, non-local, Hartree-Fock) hybrid exchange functional (B3) (Becke AD et al. 1993), with Lee-Yang-Parr correlational functional (LYP) (Lee CT et al. 1988). The basis set 6-31G $(d, p)$ with ' $d$ ' polarization functions on heavy atoms and 'p' polarization functions on hydrogen atoms are used for better description of polar bonds of molecule (Petersson DA et al. 1991; Petersson GA et al. 1988). Time dependent density functional theory (TD- 
DFT) is used to find the various electronic excitations and their nature within molecule.

\section{Results and discussion}

\subsection{Molecular geometry}

The optimized molecular structure of (exTTF) derivatives 1-4 belongs to $\mathrm{C} 1$ point group symmetry. The most optimized geometry is performed at B3LYP/6-31G $(\mathrm{d}, \mathrm{p})$ basis set of (exTTF) derivatives 1-4 molecule with atom numbering scheme is shown in Fig 1. The comparative optimized structural parameters such as bond lengths, bond angles and dihedral angles are presented in Table 1.
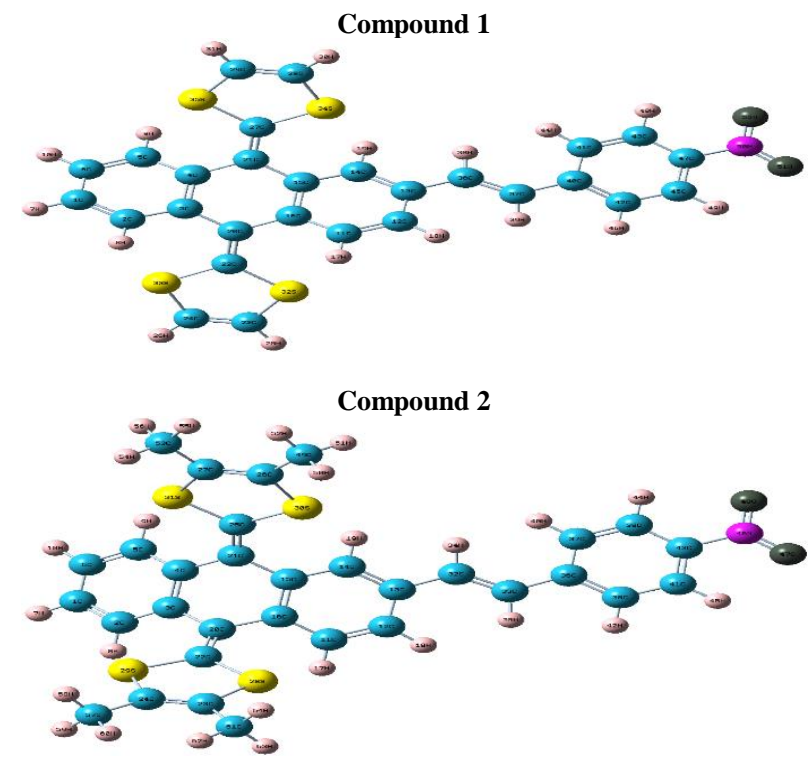
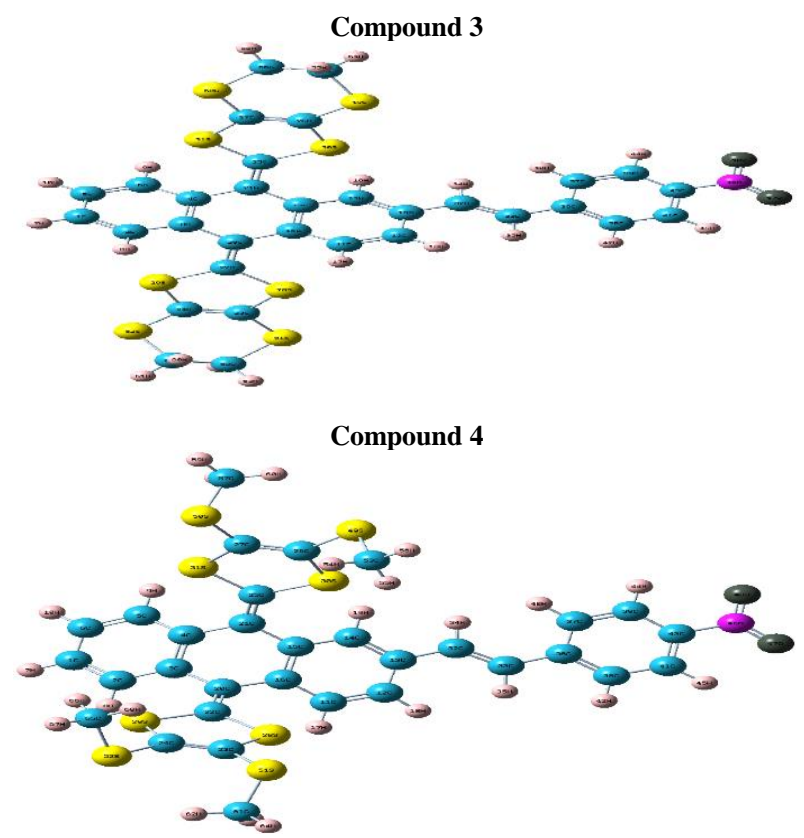

Fig. 1: Optimized Molecular Structure of (Exttf) Derivatives 1-4.

Table 1: Optimized Geometric Parameters of Compound 1

\begin{tabular}{|c|c|c|c|c|c|}
\hline \multicolumn{2}{|c|}{ Bond Length $(\AA)$} & \multicolumn{2}{|c|}{ Bond Angles $\left({ }^{\circ}\right)$} & \multicolumn{2}{|c|}{ Dihedral Angles $\left({ }^{\circ}\right)$} \\
\hline $\mathrm{R}(1,2)$ & 1.394 & $\mathrm{~A}(2,1,6)$ & 119.208 & $\mathrm{D}(6,1,2,8)$ & 178.992 \\
\hline $\mathrm{R}(1,7)$ & 1.086 & $\mathrm{~A}(6,1,7)$ & 120.945 & $\mathrm{D}(7,1,2,3)$ & 179.683 \\
\hline $\mathrm{R}(3,20)$ & 1.478 & $\mathrm{~A}(2,3,20)$ & 122.441 & $\mathrm{D}(2,1,6,10)$ & 174.408 \\
\hline $\mathrm{R}(4,21)$ & 1.476 & $\mathrm{~A}(12,11,16)$ & 122.623 & $\mathrm{D}(2,3,4,21)$ & 160.578 \\
\hline $\mathrm{R}(14,15)$ & 1.401 & $\mathrm{~A}(13,12,18)$ & 120.782 & $\mathrm{D}(20,3,4,5)$ & 161.045 \\
\hline $\mathrm{R}(15,21)$ & 1.475 & $\mathrm{~A}(12,13,36)$ & 124.002 & $\mathrm{D}(4,5,6,10)$ & 179.770 \\
\hline $\mathrm{R}(20,22)$ & 1.385 & $\mathrm{~A}(32,22,33)$ & 110.739 & $\mathrm{D}(9,5,6,1)$ & 179.312 \\
\hline $\mathrm{R}(22,33)$ & 1.793 & $\mathrm{~A}(26,24,33)$ & 116.960 & $\mathrm{D}(16,11,12,18)$ & 178.758 \\
\hline $\mathrm{R}(23,24)$ & 1.335 & $\mathrm{~A}(21,27,34)$ & 124.445 & $\mathrm{D}(12,11,16,20)$ & 165.630 \\
\hline $\mathrm{R}(28,29)$ & 1.335 & $\mathrm{~A}(34,27,35)$ & 110.769 & $\mathrm{D}(17,11,16,15)$ & 165.938 \\
\hline $\mathrm{R}(28,30)$ & 1.083 & $\mathrm{~A}(13,36,37)$ & 126.723 & $\mathrm{D}(36,13,14,15)$ & 179.084 \\
\hline $\mathrm{R}(36,37)$ & 1.352 & $\mathrm{~A}(36,37,39)$ & 118.733 & $\mathrm{D}(13,14,15,21)$ & 166.637 \\
\hline $\mathrm{R}(41,44)$ & 1.085 & $\mathrm{~A}(43,47,50)$ & 119.244 & $\mathrm{D}(19,14,15,16)$ & 166.902 \\
\hline $\mathrm{R}(47,50)$ & 1.464 & $\mathrm{~A}(47,50,51)$ & 117.801 & $\mathrm{D}(14,15,21,4)$ & 160.570 \\
\hline $\mathrm{R}(50,51)$ & 1.233 & $\mathrm{~A}(51,50,52)$ & 124.415 & $\mathrm{D}(42,45,47,50)$ & 179.925 \\
\hline
\end{tabular}

Table 2: Optimized Geometric Parameters of Compound 2

\begin{tabular}{|c|c|c|c|c|c|}
\hline \multicolumn{2}{|c|}{ Bond Length $(\AA)$} & \multicolumn{2}{|l|}{ Bond Angles $\left({ }^{\circ}\right)$} & \multicolumn{2}{|c|}{ Dihedral Angles $\left({ }^{\circ}\right)$} \\
\hline $\mathrm{R}(1,2)$ & 1.395 & $\mathrm{~A}(2,1,6)$ & 119.812 & $\mathrm{D}(20,3,4,5)$ & 177.539 \\
\hline $\mathrm{R}(1,7)$ & 1.086 & $\mathrm{~A}(6,1,7)$ & 120.426 & $\mathrm{D}(2,3,20,16)$ & 140.716 \\
\hline $\mathrm{R}(5,6)$ & 1.394 & $\mathrm{~A}(2,3,20)$ & 123.157 & $\mathrm{D}(4,3,20,22)$ & 139.492 \\
\hline $\mathrm{R}(13,14)$ & 1.407 & $\mathrm{~A}(5,4,21)$ & 123.223 & $\mathrm{D}(21,4,5,6)$ & 178.786 \\
\hline $\mathrm{R}(13,32)$ & 1.460 & $\mathrm{~A}(12,13,32)$ & 123.744 & $\mathrm{D}(12,11,16,20)$ & 178.840 \\
\hline $\mathrm{R}(14,15)$ & 1.397 & $\mathrm{~A}(14,15,21)$ & 123.245 & $\mathrm{D}(18,12,13,14)$ & 177.471 \\
\hline $\mathrm{R}(14,19)$ & 1.085 & $\mathrm{~A}(24,23,28)$ & 116.751 & $\mathrm{D}(12,13,32,34)$ & 174.867 \\
\hline $\mathrm{R}(20,22)$ & 1.367 & $\mathrm{~A}(21,25,31)$ & 124.157 & $\mathrm{D}(14,13,32,33)$ & 175.426 \\
\hline $\mathrm{R}(22,28)$ & 1.782 & $\mathrm{~A}(35,33,36)$ & 114.514 & $\mathrm{D}(19,14,15,16)$ & 176.425 \\
\hline $\mathrm{R}(23,24)$ & 1.344 & $\mathrm{~A}(39,37,40)$ & 118.664 & $\mathrm{D}(21,15,16,11)$ & 178.098 \\
\hline $\mathrm{R}(23,28)$ & 1.777 & $\mathrm{~A}(43,39,44)$ & 119.241 & $\mathrm{D}(20,22,29,24)$ & 168.033 \\
\hline $\mathrm{R}(26,49)$ & 1.503 & $\mathrm{~A}(47,46,48)$ & 124.396 & $\mathrm{D}(39,43,46,47)$ & 179.899 \\
\hline $\mathrm{R}(32,33)$ & 1.351 & $\mathrm{~A}(51,49,52)$ & 107.790 & $\mathrm{D}(20,3,4,5)$ & 177.539 \\
\hline $\mathrm{R}(43,46)$ & 1.464 & $\mathrm{~A}(24,57,60)$ & 111.346 & $\mathrm{D}(2,3,20,16)$ & 140.716 \\
\hline $\mathrm{R}(46,47)$ & 1.233 & $\mathrm{~A}(62,61,63)$ & 107.830 & $\mathrm{D}(4,3,20,22)$ & 139.492 \\
\hline
\end{tabular}


Table 3: Optimized Geometric Parameters of Compound-3

\begin{tabular}{lllll}
\hline Bond Length $(\AA)$ & \multicolumn{3}{c}{ Table 3: Optimized Geometric Parameters of Compound-3 } \\
\hline $\mathrm{R}(1,2)$ & 1.395 & $\mathrm{~A}(2,1,6)$ & 119.814 & $\mathrm{D}$ Dihedral Angles $\left(^{\circ}\right)$ \\
$\mathrm{R}(1,7)$ & 1.086 & $\mathrm{~A}(6,1,7)$ & 120.427 & $\mathrm{D}(20,3,4,5)$ \\
$\mathrm{R}(3,20)$ & 1.481 & $\mathrm{~A}(4,3,20)$ & 117.725 & $\mathrm{D}(2,3,20,16)$ \\
$\mathrm{R}(11,17)$ & 1.085 & $\mathrm{~A}(12,11,16)$ & 121.621 & $\mathrm{D}(21,4,5,6)$ \\
$\mathrm{R}(13,32)$ & 1.461 & $\mathrm{~A}(12,13,32)$ & $\mathrm{D}(12,13,32,34)$ & 141.014 \\
$\mathrm{R}(14,15)$ & 1.397 & $\mathrm{~A}(15,14,19)$ & 123.819 & $\mathrm{D}(14,13,32,33)$ \\
$\mathrm{R}(24,52)$ & 1.771 & $\mathrm{~A}(11,16,15)$ & 119.311 & $\mathrm{D}(21,15,16,11)$ \\
$\mathrm{R}(25,31)$ & 1.789 & $\mathrm{~A}(3,20,16)$ & 118.512 & $\mathrm{D}(28,23,24,52)$ \\
$\mathrm{R}(32,33)$ & 1.351 & $\mathrm{~A}(16,20,22)$ & 113.539 & $\mathrm{D}(51,23,24,29)$ \\
$\mathrm{R}(32,34)$ & 1.088 & $\mathrm{~A}(29,24,52)$ & 123.154 & $\mathrm{D}(52,24,29,22)$ \\
$\mathrm{R}(43,46)$ & 1.465 & $\mathrm{~A}(30,26,49)$ & 117.131 & $\mathrm{D}(23,24,52,65)$ \\
$\mathrm{R}(46,48)$ & 1.233 & $\mathrm{~A}(13,32,33)$ & 116.988 & $\mathrm{D}(30,26,27,50)$ \\
$\mathrm{R}(52,65)$ & 1.838 & $\mathrm{~A}(43,46,47)$ & 127.051 & $\mathrm{D}(38,41,43,46)$ \\
$\mathrm{R}(53,56)$ & 1.092 & $\mathrm{~A}(52,65,68)$ & 117.781 & $\mathrm{D}(20,3,4,5)$ \\
$\mathrm{R}(65,66)$ & 1.091 & $\mathrm{~A}(66,65,68)$ & 110.402 & $\mathrm{D}(2,3,20,16)$ \\
\hline
\end{tabular}

Table 4: Optimized Geometric Parameters of Compound-4

\begin{tabular}{lllll}
\hline Bond Length $(\AA)$ & \multicolumn{3}{c}{ Bond Angles $\left(^{\circ}\right)$} & Dihedral Angles $\left(^{\circ}\right)$ \\
\hline $\mathrm{R}(1,2)$ & 1.394 & $\mathrm{~A}(2,1,6)$ & 119.269 & $\mathrm{D}(6,1,2,8)$ \\
$\mathrm{R}(1,7)$ & 1.085 & $\mathrm{~A}(6,1,7)$ & 120.895 & $\mathrm{D}(7,1,2,3)$ \\
$\mathrm{R}(2,8)$ & 1.084 & $\mathrm{~A}(11,12,18)$ & 119.165 & $\mathrm{D}(2,1,6,10)$ \\
$\mathrm{R}(20,22)$ & 1.385 & $\mathrm{~A}(12,13,32)$ & 123.972 & $\mathrm{D}(7,1,6,5)$ \\
$\mathrm{R}(22,28)$ & 1.791 & $\mathrm{~A}(16,20,22)$ & 120.870 & $\mathrm{D}(2,3,4,21)$ \\
$\mathrm{R}(23,24)$ & 1.346 & $\mathrm{~A}(4,21,15)$ & 116.666 & $\mathrm{D}(20,3,4,5)$ \\
$\mathrm{R}(23,28)$ & 1.774 & $\mathrm{~A}(23,24,29)$ & 116.996 & $\mathrm{D}(4,5,6,10)$ \\
$\mathrm{R}(23,51)$ & 1.767 & $\mathrm{~A}(29,24,52)$ & 117.886 & $\mathrm{D}(16,11,12,18)$ \\
$\mathrm{R}(32,33)$ & 1.351 & $\mathrm{~A}(30,25,31)$ & 110.515 & $\mathrm{D}(12,11,16,20)$ \\
$\mathrm{R}(32,34)$ & 1.088 & $\mathrm{~A}(32,33,35)$ & 118.748 & $\mathrm{D}(32,13,14,15)$ \\
$\mathrm{R}(43,46)$ & 1.464 & $\mathrm{~A}(41,38,42)$ & 119.281 & $\mathrm{D}(13,14,15,21)$ \\
$\mathrm{R}(46,48)$ & 1.233 & $\mathrm{~A}(41,43,46)$ & 119.279 & $\mathrm{D}(19,14,15,16)$ \\
$\mathrm{R}(51,62)$ & 1.859 & $\mathrm{~A}(47,46,48)$ & 124.416 & $\mathrm{D}(16,15,21,25)$ \\
$\mathrm{R}(59,62)$ & 1.522 & $\mathrm{~A}(51,62,59)$ & 115.617 & $\mathrm{D}(39,43,46,47)$ \\
$\mathrm{R}(62,63)$ & 1.095 & $\mathrm{~A}(59,62,63)$ & 109.776 & $\mathrm{D}(51,23,24,29)$ \\
\hline
\end{tabular}

\subsection{Molecular electrostatic potential (MEP)}

Electrostatic potential maps are very useful three dimensional diagrams used to visualize the charge distributions and charge related properties of molecules. The MEP is typically visualized through mapping its values onto the surface reflecting the molecules boundaries so it allows us to visualize the size and shape of molecules. MEP diagram has been also used to predict the reactive sites for electrophilic and nucleophilic attack, and in studies of biological recognition and hydrogen bonding interactions (Scrocco $\mathrm{E}$ et al. 1978; Murray JS et al. 1996). The MEP of the studied compounds calculated using B3LYP method with 6-31G(d,p) basis set is shown in Fig 2. This figure provides a visual representation of the chemically active sites and comparative reactivity of atoms. Potential increases in the order red < orange $<$ yellow $<$ green $<$ blue. For all the studied compounds, and as seen from the figure 2 that, the regions exhibiting the negative electrostatic potential are localized near the nitro group while the regions presenting the positive potential are localized vicinity of the hydrogen atoms of alkyl and cycled groups.

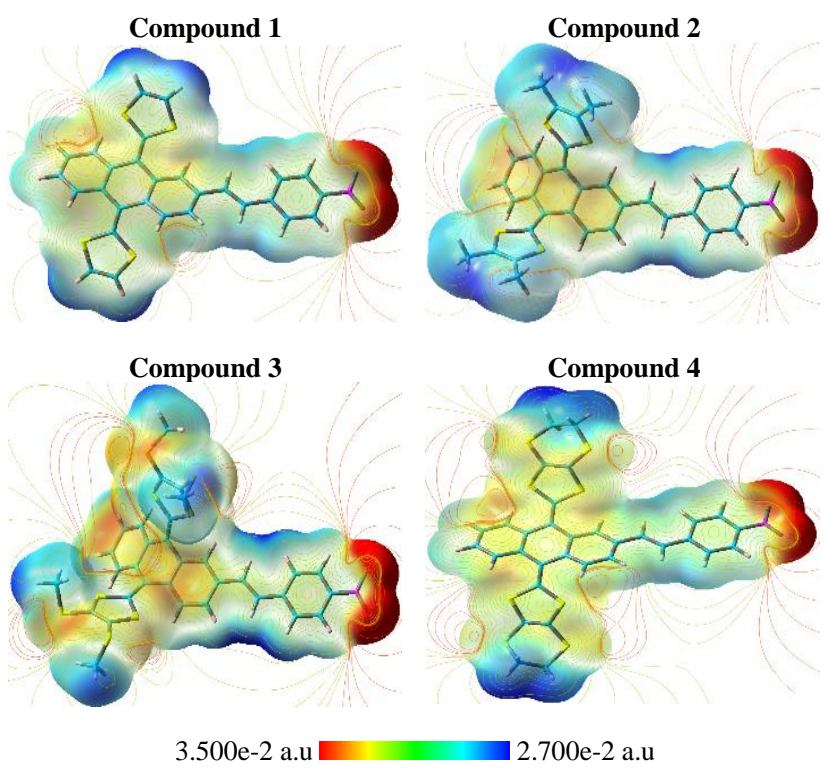

Fig. 2: Molecular Electrostatic Potential Surface of (Exttf) Derivatives 1-4.

\subsection{Frontier molecular orbitals (FMOs)}

In principle, there are several ways to calculate the excitation energies. The simplest one involves the difference between the highest occupied molecular orbital (HOMO) and the lowest unoccupied molecular orbital (LUMO) of a neutral system, and is a key parameter determining molecular properties. There are lots of applications available for the use of the HOMO and LUMO energy gap as a quantum chemical descriptor. The frozen orbital approximation and the ground state properties are used to calculate the excitation values. This method is very practical, particularly for calculating large systems (Curtiss LA et al. 1998). Rigorously, the density functional methods (which are based on Hohenberg and Kohn theorem (Hohenberg $\mathrm{P}$ et al. 1964)) are designed to yield total energies. The Eigen values of LUMO and HOMO and their energy gap reflect the 
chemical activity of the molecule. The HOMO-LUMO plots of compound-2 are given in Fig 3 .

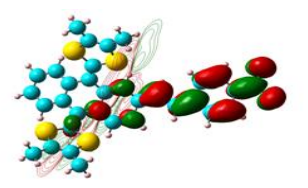

(Ground state)

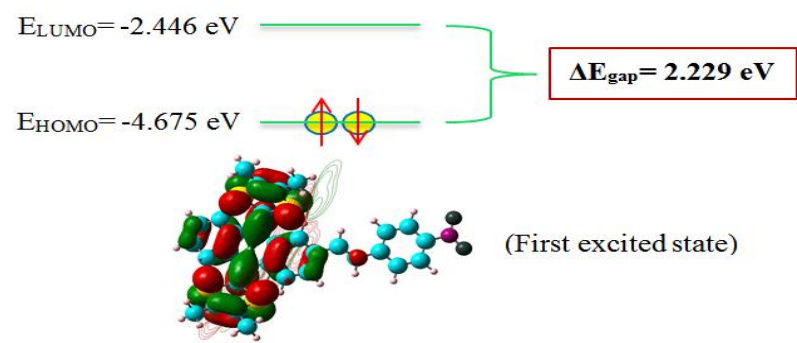

Fig. 3: HOMO-LUMO Structure with the Energy Level Diagram of Compound-2.

\subsection{Global reactivity descriptors}

Within the conceptual framework of DFT, the chemical potential ( $\mu$ ) defined as Eq. (1) (Srivastava A et al. 2012), can measure the escape tendency of an electron from equilibrium.

$$
\mu=1 / 2\left(\varepsilon_{\text {Hомо }}+\varepsilon_{\text {LUMO }}\right)=-\chi
$$

Where $-\chi$ is the electronegativity [23].

The global hardness $(\eta)$ is defined via Eq. (2) (Ayres PW et al. 2000), indicating the resistance to charge transfer. However, the softness (s) defined by Eq. (3) can measure the ease of charge transfer (Parthasarathi R et al. 2003). In general, a molecule with a high value of $g$ and a low value of $s$, will show an inert characteristic of electrophilic attack.

$$
\begin{aligned}
& \eta=1 / 2\left(\varepsilon_{\text {LUMO }}-\varepsilon_{\text {номо }}\right) \\
& S=1 / 2 \eta
\end{aligned}
$$

In Eqs. (1) And (2), $\varepsilon$ номо and $\varepsilon$ LUMо are the energies of the highest occupied and the lowest unoccupied molecular orbitals (HOMO and LUMO), respectively.

The electrophilicity index $(\omega)$ represents the propensity of a molecule to accept electrons from the surrounding molecules. $\omega$ is calculated using Eq. (4) (Srivastava A et al. 2012; Ayres PW et al. 2000; Parthasarathi R et al. 2003):

$$
\omega=\mu^{2} / 2 \eta
$$

A molecule as the good electrophile is characterized by high values of $\mu$ and $\omega$; however, a molecule as the good nucleophile is characterized by low values of $\mu$ and $\omega$. Table 5 presents the values of electronegativity $(\chi)$, chemical potential $(\mu)$, global hardness $(\eta)$, global softness (S) and global electrophilicity index $(\omega)$.

Table 5: Quantum Chemical Descriptors of (Exttf) Derivatives 1-4

\begin{tabular}{lllll}
\hline $\begin{array}{l}\text { Para- } \\
\text { mètres }\end{array}$ & $\begin{array}{l}\text { Compound } \\
\text { E }\end{array}$ & $\begin{array}{l}\text { Compound } \\
2\end{array}$ & $\begin{array}{l}\text { Compound } \\
3\end{array}$ & $\begin{array}{l}\text { Compound } \\
4\end{array}$ \\
\hline $\begin{array}{l}\mathrm{E}_{\text {HOMO }} \\
(\mathrm{eV})\end{array}$ & -4.772 & -4.675 & -4.972 & -4.796 \\
$\mathrm{E}_{\mathrm{LUMO}}$ & -2.494 & -2.446 & -2.540 & -2.493 \\
$(\mathrm{eV})$ & & 2.229 & 2.432 & 2.303 \\
$\Delta \mathrm{E}_{\mathrm{gap}}(\mathrm{eV})$ & 2.278 & 4.675 & 4.972 & 4.796 \\
$\mathrm{IE}(\mathrm{eV})$ & 4.772 & 2.446 & 2.540 & 2.493 \\
$\mathrm{~A}(\mathrm{eV})$ & 2.494 & -3.560 & -3.756 & -3.645 \\
$\mu(\mathrm{eV})$ & -3.633 & 3.560 & 3.756 & 3.645 \\
$\chi(\mathrm{eV})$ & 3.633 & 1.115 & 1.216 & 1.152 \\
$\eta(\mathrm{eV})$ & 1.139 & & & \\
\hline
\end{tabular}

\begin{tabular}{lllll}
\hline $\mathrm{S}(\mathrm{eV})$ & 0.439 & 0.449 & 0.411 & 0.434 \\
$\omega(\mathrm{eV})$ & 5.796 & 5.686 & 5.800 & 5.766 \\
\hline
\end{tabular}

As presented in table 5, the compound which have the lowest energetic gap is the compound $2\left(\Delta \mathrm{E}_{\text {gap }}=2.229 \mathrm{eV}\right)$. This lower gap allows it to be the softest molecule. The compound that have the highest energy gap is the compound $3\left(\Delta \mathrm{E}_{\mathrm{gap}}=2.432 \mathrm{eV}\right)$. The compound that has the highest HOMO energy is the compound 2 $\left(\mathrm{E}_{\text {HOMO }}=-4.675 \mathrm{eV}\right)$. This higher energy allows it to be the best electron donor. The compound that has the lowest LUMO energy is the compound $3\left(E_{\text {LUMO }}=-2.540 \mathrm{eV}\right)$ which signifies that it can be the best electron acceptor. The two properties like I (potential ionization) and A (affinity) are so important, the determination of these two properties allow us to calculate the absolute electronegativity $(\chi)$ and the absolute hardness $(\eta)$. These two parameters are related to the one-electron orbital energies of the HOMO and LUMO respectively. Compound 2 has lowest value of the potential ionization $(\mathrm{I}=4.675 \mathrm{eV})$, so that will be the better electron donor. Compound 3 has the largest value of the affinity $(\mathrm{A}=2.540 \mathrm{eV})$, so it is the better electron acceptor. The chemical reactivity varies with the structural of molecules. Chemical hardness (softness) value of compound $2(\eta=1.115 \mathrm{eV}, \mathrm{S}=0.449 \mathrm{eV})$ is lesser (greater) among all the molecules. Thus, compound 2 is found to be more reactive than all the compounds. Compound 3 possesses higher electronegativity value $(\chi=3.756 \mathrm{eV})$ than all compounds so; it is the best electron acceptor. The value of $\omega$ for compound $3(\omega=5.800 \mathrm{eV})$ indicates that it is the stronger electrophiles than all compounds. Compound 2 has the smaller frontier orbital gap so, it is more polarizable and is associated with a high chemical reactivity, low kinetic stability and is also termed as soft molecule.

\subsection{Natural bond orbital analysis (NBO)}

The natural bond orbital analysis reveals the stabilizing interactions between filled and unoccupied orbitals and destabilizing interactions between filled orbitals can be obtained from this analysis (Reed AE et al. 1988; Foster JP et al. 1980; Weinhold F et al. 2005). The various second order interactions between the filled and unoccupied orbitals are investigated using DFT level computation which gives a measure of the delocalization or hyper-conjugation. NBO analysis furnish the most specific possible 'natural Lewis structure' picture of $j$, because all orbital details are mathematically chosen to include the highest possible percentage of the electron density. Delocalization of electron density between occupied Lewis-type (bond or lone pair) NBO orbitals and formally unoccupied (antibond or Rydberg) non-Lewis NBO orbitals corresponds to a stabilizing donor-acceptor interaction. The NBO method also gives information about interactions in both filled and virtual orbital spaces that could enhance the analysis of intra- and intermolecular interactions (Reed AE et al. 1988; Foster JP et al. 1980; Weinhold F et al. 2005; Ravikumar $\mathrm{C}$ et al. 2008). The interactions due to electron delocalization are generally analyzed by selecting a number of bonding and antibonding NBO's. For each donor NBO (i) and acceptor NBO (j) the stabilization energy $E^{(2)}$ is associated with $i-j$ delocalization is given by the following Eq. (5),

$$
\mathrm{E}^{(2)}=\Delta \mathrm{E}_{\mathrm{ij}}=\mathrm{q}_{\mathrm{i}} \frac{F^{2}(\mathrm{i}, \mathrm{j})}{\varepsilon_{\mathrm{j}}-\varepsilon_{\mathrm{i}}}
$$

Where, $\mathrm{q}_{\mathrm{i}}$ is the donor orbital occupancy, $\varepsilon_{\mathrm{i}}$ and $\varepsilon_{\mathrm{j}}$ are diagonal elements and $\mathrm{F}(\mathrm{i}, \mathrm{j})$ is the off diagonal NBO Fock matrix element. The second-order perturbation theory analysis of Fock matrix in NBO basis of (exTTF) derivatives [1-4] is given in Tables 6-9. In NBO analysis large $\mathrm{E}^{(2)}$ value shows the intensive interaction between electron-donors and electron-acceptors and greater the extent of conjugation of the whole system (Arul Dhas D et al. 2010). 
Table 6: Second Order Perturbation Theory Analysis of Fock Matrix on NBO of Compound 1

\begin{tabular}{|c|c|c|c|c|c|c|}
\hline Donor(i) & ED/e & Acceptor(j) & ED/e & $\mathrm{E}(2) \mathrm{Kcal} / \mathrm{mol}$ & $E(j)-E(i)$ a.u & $F(i . j)$ a.u \\
\hline LP (3) O52 & 1.45211 & $\pi *(\mathrm{~N} 50-\mathrm{O} 51)$ & 0.63882 & 161.75 & 0.14 & 0.138 \\
\hline$\pi(\mathrm{C} 45-\mathrm{C} 47)$ & 1.63996 & $\pi *(\mathrm{~N} 50-\mathrm{O} 51)$ & 0.63882 & 26.32 & 0.15 & 0.06 \\
\hline$\pi(\mathrm{C} 40-\mathrm{C} 42)$ & 1.59171 & $\pi *(\mathrm{C} 45-\mathrm{C} 47)$ & 0.39265 & 25.12 & 0.27 & 0.074 \\
\hline LP (2) S33 & 1.73598 & $\pi^{*}(\mathrm{C} 23-\mathrm{C} 24)$ & 0.21626 & 22.15 & 0.26 & 0.068 \\
\hline LP (2) S35 & 1.74186 & $\pi *(\mathrm{C} 28-\mathrm{C} 29)$ & 0.21518 & 22.04 & 0.26 & 0.068 \\
\hline LP (2) S32 & 1.73773 & $\pi *(\mathrm{C} 23-\mathrm{C} 24)$ & 0.21626 & 22.01 & 0.26 & 0.068 \\
\hline$\pi(\mathrm{C} 15-\mathrm{C} 16)$ & 1.56396 & $\pi *(\mathrm{C} 13-\mathrm{C} 14)$ & 0.40715 & 21.68 & 0.27 & 0.069 \\
\hline$\pi(\mathrm{C} 1-\mathrm{C} 6)$ & 1.65841 & $\pi *(\mathrm{C} 2-\mathrm{C} 3)$ & 0.37656 & 20.51 & 0.28 & 0.068 \\
\hline$\pi(\mathrm{C} 45-\mathrm{C} 47)$ & 1.63996 & $\pi *(\mathrm{C} 41-\mathrm{C} 43)$ & 0.27367 & 20.31 & 0.29 & 0.071 \\
\hline$\pi(\mathrm{C} 4-\mathrm{C} 5)$ & 1.64443 & $\pi *(\mathrm{C} 1-\mathrm{C} 6)$ & 0.33938 & 20.23 & 0.28 & 0.068 \\
\hline$\pi(\mathrm{C} 13-\mathrm{C} 14)$ & 1.62148 & $\pi *(\mathrm{C} 15-\mathrm{C} 16)$ & 0.42590 & 19.29 & 0.28 & 0.066 \\
\hline LP (2) O51 & 1.89930 & $\sigma^{*}(\mathrm{~N} 50-\mathrm{O} 52)$ & 0.05686 & 19.22 & 0.70 & 0.105 \\
\hline LP (2) O52 & 1.89948 & $\sigma^{*}(\mathrm{~N} 50-\mathrm{O} 51)$ & 0.05678 & 19.21 & 0.70 & 0.105 \\
\hline$\pi(\mathrm{C} 11-\mathrm{C} 12)$ & 1.69363 & $\pi *(\mathrm{C} 13-\mathrm{C} 14)$ & 0.40715 & 18.36 & 0.29 & 0.066 \\
\hline$\pi(\mathrm{C} 2-\mathrm{C} 3)$ & 1.64606 & $\pi *(\mathrm{C} 4-\mathrm{C} 5)$ & 0.37628 & 18.07 & 0.28 & 0.064 \\
\hline$\pi(\mathrm{C} 4-\mathrm{C} 5)$ & 1.64443 & $\pi *(\mathrm{C} 2-\mathrm{C} 3)$ & 0.37656 & 18.04 & 0.28 & 0.064 \\
\hline$\pi(\mathrm{C} 15-\mathrm{C} 16)$ & 1.56396 & $\pi *(\mathrm{C} 20-\mathrm{C} 22)$ & 0.36587 & 16.77 & 0.25 & 0.059 \\
\hline$\pi(\mathrm{C} 36-\mathrm{C} 37)$ & 1.84323 & $\pi^{*}(\mathrm{C} 40-\mathrm{C} 42)$ & 0.37418 & 14.59 & 0.29 & 0.062 \\
\hline $\mathrm{LP}(2) \mathrm{O} 51$ & 1.89930 & $\sigma^{*}(\mathrm{C} 47-\mathrm{N} 50)$ & 0.10089 & 12.22 & 0.58 & 0.075 \\
\hline$\sigma(\mathrm{C} 29-\mathrm{H} 31)$ & 1.97534 & $\sigma^{*}(\mathrm{C} 28-\mathrm{S} 34)$ & 0.03061 & 5.14 & 0.78 & 0.056 \\
\hline
\end{tabular}

Table 7: Second Order Perturbation Theory Analysis of Fock Matrix on NBO of Compound 2

\begin{tabular}{|c|c|c|c|c|c|c|}
\hline Donor(i) & ED/e & Acceptor(j) & ED/e & $\mathrm{E}(2) \mathrm{Kcal} / \mathrm{mol}$ & $E(j)-E(i)$ a.u & $F(i . j)$ a.u \\
\hline LP (3) O48 & 1.45234 & $\pi *(\mathrm{~N} 46-\mathrm{O} 47)$ & 0.63897 & 161.71 & 0.14 & 0.138 \\
\hline$\pi(\mathrm{C} 41-\mathrm{C} 43)$ & 1.64036 & $\pi^{*}(\mathrm{~N} 46-\mathrm{O} 47)$ & 0.63897 & 26.39 & 0.15 & 0.060 \\
\hline$\pi(\mathrm{C} 36-\mathrm{C} 38)$ & 1.59169 & $\pi *(\mathrm{C} 41-\mathrm{C} 43)$ & 0.39290 & 25.18 & 0.27 & 0.074 \\
\hline$\pi(\mathrm{C} 15-\mathrm{C} 16)$ & 1.58362 & $\pi *(\mathrm{C} 13-\mathrm{C} 14)$ & 0.39386 & 21.66 & 0.27 & 0.069 \\
\hline LP (2) S29 & 1.76445 & $\pi^{*}(\mathrm{C} 23-\mathrm{C} 24)$ & 0.23484 & 20.48 & 0.27 & 0.067 \\
\hline$\pi(\mathrm{C} 4-\mathrm{C} 5)$ & 1.64934 & $\pi^{*}(\mathrm{C} 1-\mathrm{C} 6)$ & 0.33916 & 20.41 & 0.28 & 0.068 \\
\hline LP (2) S31 & 1.76968 & $\pi^{*}(\mathrm{C} 26-\mathrm{C} 27)$ & 0.23408 & 20.37 & 0.27 & 0.066 \\
\hline$\pi(\mathrm{C} 37-\mathrm{C} 39)$ & 1.68142 & $\pi^{*}(\mathrm{C} 36-\mathrm{C} 38)$ & 0.37378 & 20.24 & 0.29 & 0.069 \\
\hline$\pi(\mathrm{C} 1-\mathrm{C} 6)$ & 1.65916 & $\pi^{*}(\mathrm{C} 4-\mathrm{C} 5)$ & 0.36105 & 20.16 & 0.28 & 0.068 \\
\hline LP (2) O47 & 1.89937 & $\sigma^{*}(\mathrm{~N} 46-\mathrm{O} 48)$ & 0.05686 & 19.22 & 0.70 & 0.105 \\
\hline$\pi(\mathrm{C} 2-\mathrm{C} 3)$ & 1.65046 & $\pi *(\mathrm{C} 4-\mathrm{C} 5)$ & 0.36105 & 19.19 & 0.28 & 0.066 \\
\hline$\pi(\mathrm{C} 13-\mathrm{C} 14)$ & 1.61791 & $\pi^{*}(\mathrm{C} 11-\mathrm{C} 12)$ & 0.30719 & 18.71 & 0.28 & 0.066 \\
\hline$\pi(\mathrm{C} 11-\mathrm{C} 12)$ & 1.68791 & $\pi *(\mathrm{C} 13-\mathrm{C} 14)$ & 0.39386 & 18.67 & 0.28 & 0.066 \\
\hline LP (2) S31 & 1.76968 & $\pi *(\mathrm{C} 21-\mathrm{C} 25)$ & 0.31877 & 18.59 & 0.28 & 0.066 \\
\hline$\pi(\mathrm{C} 32-\mathrm{C} 33)$ & 1.84413 & $\pi *(\mathrm{C} 36-\mathrm{C} 38)$ & 0.37378 & 14.70 & 0.29 & 0.062 \\
\hline $\mathrm{LP}(2) \mathrm{O} 47$ & 1.89937 & $\sigma^{*}(\mathrm{C} 43-\mathrm{N} 46)$ & 0.10079 & 12.20 & 0.58 & 0.075 \\
\hline LP (2) O48 & 1.89956 & $\sigma^{*}(\mathrm{C} 43-\mathrm{N} 46)$ & 0.10079 & 12.18 & 0.58 & 0.075 \\
\hline$\pi(\mathrm{C} 4-\mathrm{C} 5)$ & 1.64934 & $\pi *(\mathrm{C} 21-\mathrm{C} 25)$ & 0.31877 & 11.43 & 0.27 & 0.050 \\
\hline$\pi(\mathrm{N} 46-\mathrm{O} 47)$ & 1.98568 & $\pi *(\mathrm{~N} 46-\mathrm{O} 47)$ & 0.63897 & 7.59 & 0.32 & 0.053 \\
\hline$\pi(\mathrm{C} 20-\mathrm{C} 22)$ & 1.88302 & $\pi *(\mathrm{C} 15-\mathrm{C} 16)$ & 0.41223 & 7.46 & 0.33 & 0.048 \\
\hline
\end{tabular}

Table 8: Second Order Perturbation Theory Analysis of Fock Matrix on NBO of Compound 3

\begin{tabular}{|c|c|c|c|c|c|c|}
\hline Donor(i) & ED/e & Acceptor(j) & ED/e & $\mathrm{E}(2) \mathrm{Kcal} / \mathrm{mol}$ & $E(j)-E(i)$ a.u & $F(i . j)$ a.u \\
\hline LP (3) O47 & 1.45123 & $\pi^{*}(\mathrm{~N} 46-\mathrm{O} 48)$ & 0.63738 & 162.21 & 0.14 & 0.138 \\
\hline$\pi(\mathrm{C} 41-\mathrm{C} 43)$ & 1.64022 & $\pi^{*}(\mathrm{~N} 46-\mathrm{O} 48)$ & 0.63738 & 29.29 & 0.15 & 0.063 \\
\hline$\pi(\mathrm{C} 36-\mathrm{C} 38)$ & 1.59310 & $\pi^{*}(\mathrm{C} 41-\mathrm{C} 43)$ & 0.39029 & 24.93 & 0.27 & 0.074 \\
\hline LP (2) S31 & 1.74859 & $\pi *(\mathrm{C} 26-\mathrm{C} 27)$ & 0.30470 & 22.72 & 0.23 & 0.066 \\
\hline LP (2) S28 & 1.74778 & $\pi *(\mathrm{C} 23-\mathrm{C} 24)$ & 0.30636 & 22.55 & 0.23 & 0.066 \\
\hline LP (2) S30 & 1.75763 & $\pi *(\mathrm{C} 26-\mathrm{C} 27)$ & 0.30470 & 21.46 & 0.24 & 0.064 \\
\hline$\pi(\mathrm{C} 15-\mathrm{C} 16)$ & 1.58525 & $\pi *(\mathrm{C} 13-\mathrm{C} 14)$ & 0.39317 & 21.41 & 0.27 & 0.069 \\
\hline$\pi(\mathrm{C} 13-\mathrm{C} 14)$ & 1.61557 & $\pi *(\mathrm{C} 15-\mathrm{C} 16)$ & 0.41382 & 20.64 & 0.28 & 0.068 \\
\hline$\pi(\mathrm{C} 37-\mathrm{C} 39)$ & 1.67937 & $\pi *(\mathrm{C} 36-\mathrm{C} 38)$ & 0.37284 & 20.30 & 0.28 & 0.069 \\
\hline$\pi(\mathrm{C} 1-\mathrm{C} 6)$ & 1.65727 & $\pi *(\mathrm{C} 2-\mathrm{C} 3)$ & 0.36062 & 20.27 & 0.28 & 0.068 \\
\hline$\pi(\mathrm{C} 41-\mathrm{C} 43)$ & 1.64022 & $\pi *(\mathrm{C} 37-\mathrm{C} 39)$ & 0.27311 & 20.26 & 0.29 & 0.071 \\
\hline$\pi(\mathrm{C} 4-\mathrm{C} 5)$ & 1.65043 & $\pi^{*}(\mathrm{C} 1-\mathrm{C} 6)$ & 0.33308 & 20.17 & 0.28 & 0.068 \\
\hline LP (2) O47 & 1.89914 & $\sigma^{*}(\mathrm{~N} 46-\mathrm{O} 48)$ & 0.05684 & 19.23 & 0.70 & 0.105 \\
\hline LP (2) O48 & 1.89930 & $\sigma^{*}(\mathrm{~N} 46-\mathrm{O} 47)$ & 0.05678 & 19.22 & 0.70 & 0.105 \\
\hline$\pi(\mathrm{C} 4-\mathrm{C} 5)$ & 1.65043 & $\pi *(\mathrm{C} 2-\mathrm{C} 3)$ & 0.36062 & 19.20 & 0.28 & 0.066 \\
\hline$\pi(\mathrm{C} 2-\mathrm{C} 3)$ & 1.65113 & $\pi *(\mathrm{C} 4-\mathrm{C} 5)$ & 0.36010 & 19.17 & 0.28 & 0.066 \\
\hline$\pi(\mathrm{C} 11-\mathrm{C} 12)$ & 1.68350 & $\pi^{*}(\mathrm{C} 15-\mathrm{C} 16)$ & 0.41382 & 18.89 & 0.29 & 0.067 \\
\hline$\pi(\mathrm{C} 41-\mathrm{C} 43)$ & 1.64022 & $\pi *(\mathrm{C} 36-\mathrm{C} 38)$ & 0.37284 & 17.43 & 0.29 & 0.064 \\
\hline LP (2) O47 & 1.89914 & $\sigma^{*}(\mathrm{C} 43-\mathrm{N} 46)$ & 0.10131 & 12.27 & 0.58 & 0.075 \\
\hline LP (2) O48 & 1.89930 & $\sigma *(\mathrm{C} 43-\mathrm{N} 46)$ & 0.10131 & 12.25 & 0.58 & 0.075 \\
\hline
\end{tabular}

Table 9: Second Order Perturbation Theory Analysis of Fock Matrix on NBO of Compound 4

\begin{tabular}{|c|c|c|c|c|c|c|}
\hline Donor(i) & ED/e & Acceptor(j) & ED/e & $\mathrm{E}(2) \mathrm{Kcal} / \mathrm{mol}$ & $E(j)-E(i)$ a.u & $F(i . j)$ a.u \\
\hline LP (3) O48 & 1.45188 & $\pi^{*}(\mathrm{~N} 46-\mathrm{O} 47)$ & 0.63845 & 161.81 & 0.14 & 0.138 \\
\hline$\pi(\mathrm{C} 41-\mathrm{C} 43)$ & 1.64003 & $\pi^{*}(\mathrm{~N} 46-\mathrm{O} 47)$ & 0.63845 & 26.29 & 0.15 & 0.060 \\
\hline$\pi(\mathrm{C} 36-\mathrm{C} 38)$ & 1.59191 & $\pi^{*}(\mathrm{C} 41-\mathrm{C} 43)$ & 0.39203 & 25.06 & 0.27 & 0.074 \\
\hline$\pi(\mathrm{C} 15-\mathrm{C} 16)$ & 1.56299 & $\pi^{*}(\mathrm{C} 13-\mathrm{C} 14)$ & 0.40770 & 21.55 & 0.27 & 0.069 \\
\hline LP (2) S29 & 1.75234 & $\pi^{*}(\mathrm{C} 23-\mathrm{C} 24)$ & 0.37016 & 20.78 & 0.24 & 0.065 \\
\hline LP (2) S31 & 1.75740 & $\pi^{*}(\mathrm{C} 26-\mathrm{C} 27)$ & 0.36896 & 20.64 & 0.24 & 0.064 \\
\hline$\pi(\mathrm{C} 1-\mathrm{C} 6)$ & 1.65818 & $\pi *(\mathrm{C} 2-\mathrm{C} 3)$ & 0.37531 & 20.48 & 0.28 & 0.068 \\
\hline$\pi(\mathrm{C} 1-\mathrm{C} 6)$ & 1.65818 & $\pi *(\mathrm{C} 4-\mathrm{C} 5)$ & 0.37527 & 20.44 & 0.28 & 0.068 \\
\hline
\end{tabular}




\begin{tabular}{|c|c|c|c|c|c|c|}
\hline$\pi(\mathrm{C} 37-\mathrm{C} 39)$ & 1.68024 & $\pi^{*}(\mathrm{C} 36-\mathrm{C} 38)$ & 0.37357 & 20.25 & 0.28 & 0.069 \\
\hline$\pi(\mathrm{C} 2-\mathrm{C} 3)$ & 1.64514 & $\pi^{*}(\mathrm{C} 1-\mathrm{C} 6)$ & 0.33413 & 19.96 & 0.29 & 0.068 \\
\hline$\pi(\mathrm{C} 13-\mathrm{C} 14)$ & 1.61725 & $\pi^{*}(\mathrm{C} 15-\mathrm{C} 16)$ & 0.42720 & 19.46 & 0.28 & 0.066 \\
\hline LP (2) O47 & 1.89929 & $\sigma^{*}(\mathrm{~N} 46-\mathrm{O} 48)$ & 0.05685 & 19.23 & 0.70 & 0.105 \\
\hline LP (2) S49 & 1.85788 & $\pi *(\mathrm{C} 26-\mathrm{C} 27)$ & 0.36896 & 19.03 & 0.24 & 0.064 \\
\hline$\pi(\mathrm{C} 11-\mathrm{C} 12)$ & 1.68803 & $\pi^{*}(\mathrm{C} 13-\mathrm{C} 14)$ & 0.40770 & 18.54 & 0.29 & 0.067 \\
\hline$\pi(\mathrm{C} 2-\mathrm{C} 3)$ & 1.64514 & $\pi^{*}(\mathrm{C} 4-\mathrm{C} 5)$ & 0.37527 & 18.08 & 0.28 & 0.064 \\
\hline$\pi(\mathrm{C} 4-\mathrm{C} 5)$ & 1.64379 & $\pi^{*}(\mathrm{C} 2-\mathrm{C} 3)$ & 0.37531 & 18.07 & 0.28 & 0.064 \\
\hline LP (2) S28 & 1.75597 & $\pi^{*}(\mathrm{C} 20-\mathrm{C} 22)$ & 0.35874 & 17.01 & 0.27 & 0.063 \\
\hline$\pi(\mathrm{C} 15-\mathrm{C} 16)$ & 1.56299 & $\pi^{*}(\mathrm{C} 20-\mathrm{C} 22)$ & 0.35874 & 16.94 & 0.25 & 0.060 \\
\hline$\pi(\mathrm{C} 13-\mathrm{C} 14)$ & 1.61725 & $\pi^{*}(\mathrm{C} 32-\mathrm{C} 33)$ & 0.14392 & 15.85 & 0.29 & 0.064 \\
\hline$\pi(\mathrm{C} 32-\mathrm{C} 33)$ & 1.84302 & $\pi *(\mathrm{C} 36-\mathrm{C} 38)$ & 0.37357 & 14.53 & 0.29 & 0.062 \\
\hline
\end{tabular}

The intra molecular interaction for the title compounds is formed by the orbital overl ap between: $\pi(\mathrm{C} 45-\mathrm{C} 47)$ and $\pi *(\mathrm{~N} 50-\mathrm{O} 51)$ for compound $1, \pi(\mathrm{C} 41-\mathrm{C} 43)$ and $\pi *(\mathrm{~N} 46-\mathrm{O} 47)$ for compound 2 , $\pi(\mathrm{C} 41-\mathrm{C} 43)$ and $\pi^{*}(\mathrm{~N} 46-\mathrm{O} 48)$ for compound 3 and $\pi(\mathrm{C} 41-\mathrm{C} 43)$ and $\pi^{*}(\mathrm{~N} 46-\mathrm{O} 47)$ for compound 4 respectively, which result into intermolecular charge transfer (ICT) causing stabilization of the system. The intra molecular hyper conjugative interactions of $\pi(\mathrm{C} 45-\mathrm{C} 47)$ to $\pi^{*}(\mathrm{~N} 50-\mathrm{O} 51)$ for compound $1, \pi(\mathrm{C} 41-\mathrm{C} 43)$ to $\pi^{*}(\mathrm{~N} 46-\mathrm{O} 47)$ for compound $2, \pi(\mathrm{C} 41-\mathrm{C} 43)$ to $\pi^{*}(\mathrm{~N} 46-\mathrm{O} 48)$ for compound 3 and $\pi(\mathrm{C} 41-\mathrm{C} 43)$ to $\pi *(\mathrm{~N} 46-\mathrm{O} 47)$ for compound 4 lead to highest stabilization of 26.32, 26.39, 29.29 and $26.29 \mathrm{~kJ} \mathrm{~mol}^{-1}$ respectively. In case of LP (3) O52 orbital to the $\pi^{*}(\mathrm{~N} 50-\mathrm{O} 51)$ for compound 1, LP (3) O48 orbital to $\pi *(\mathrm{~N} 46-\mathrm{O} 47)$ for compound 2 , LP (3) O47 orbital to $\pi^{*}(\mathrm{~N} 46-\mathrm{O} 48)$ for compound 3, LP (3) O48 orbital to $\pi^{*}(\mathrm{~N} 46-\mathrm{O} 47)$ for compound 4 respectively, show the stabilization energy of $161.75,161.71,162.21$ and $161.81 \mathrm{~kJ} \mathrm{~mol}^{-1}$ respectively.

\subsection{Nonlinear optical properties (NLO)}

As hyperpolarizability is difficult task to measure directly, therefore computational calculation is an alternate choice and provides another method to investigate extensive properties of materials. Polarizabilities and hyperpolarizabilities are described to response of a system in the presence of an applied electric field (Ayres PW et al. 2000) [29]. They determine the strength of molecular interactions (long-range intermolecular induction, dispersion forces, etc.), cross sections of different scattering and collision processes, as well as the non-linear optical (NLO) properties of the system (Sun Y et al. 2003; Hald K et al. 2003). First hyperpolarizability $\left(\beta_{0}\right)$ is a third rank tensor that can be described by a $3 \times 3 \times 3$ matrix. The 27 components of the 3D-matrix can be reduced to 10 components due to the Kleinmann symmetry (Kleinmann DA et al. 1962). The components of $\beta_{0}$ are defined as the coefficients in the Taylor series expansion of the energy in the external electric field. When the external electric field is weak and homogeneous this expansion becomes:

$$
E=E^{0}-\mu_{i} F_{i}-1 / 2 \alpha_{i j} F_{i} F_{j}-1 / 6 \beta_{i j k} F_{i} F_{j} F_{k}+\ldots
$$

Where $E_{0}$ is the energy of the unperturbed molecules, $F_{i}$ is the field at the origin and $\mu_{\mathrm{i}}, \alpha \mathrm{ij}, \beta_{\mathrm{ijk}}$ are the components of dipole moment, polarizability, and first hyperpolarizability respectively. The total dipole moment $\left(\mu_{0}\right)$, the mean polarizability $\left(\left|\alpha_{0}\right|\right)$, the anisotropy of the polarizability $(\Delta \alpha)$ and the total first hyperpolarizability $\left(\beta_{0}\right)$ using $\mathrm{x}, \mathrm{y}, \mathrm{z}$ components are defined as (Sun $\mathrm{Y}$ et al. 2003).

$$
\begin{aligned}
& \mu_{0}=\left[\mu_{x}^{2}+\mu_{y}^{2}+\mu_{z}^{2}\right]^{1 / 2} \\
& \left|\alpha_{0}\right|=1 / 3\left(\alpha_{x x}+\alpha_{y y}+\alpha_{z z}\right) \\
& \Delta \alpha=2^{-1 / 2}\left[\left(\alpha_{x x}-\alpha_{y y}\right)^{2}+\left(\alpha_{y y}-\alpha_{z z}\right)^{2}+\left(\alpha_{z z}-\alpha_{x x}\right)^{2}+6 \alpha_{x z}^{2}+6 \alpha_{x y}^{2}+6 \alpha_{y z}^{2}\right]^{1 / 2} \\
& \beta_{0}=\left(\beta_{x}^{2}+\beta_{y}^{2}+\beta_{z}^{2}\right)^{1 / 2}
\end{aligned}
$$

Where

$$
\beta_{x}=\beta_{x x x}+\beta_{x y z}+\beta_{x z z}
$$

$$
\begin{aligned}
& \beta_{y}=\beta_{y y y}+\beta_{x x y}+\beta_{y z z} \\
& \beta_{z}=\beta_{z z z}+\beta_{x x z}+\beta_{y y z}
\end{aligned}
$$

The calculated dipole moment $\left(\mu_{0}\right)$, mean polarizability $\left(\left|\alpha_{0}\right|\right)$, ani-

\begin{tabular}{|c|c|c|c|c|}
\hline Parameters & $\begin{array}{l}\text { Compound } \\
1\end{array}$ & $\begin{array}{l}\text { Compound } \\
2\end{array}$ & $\begin{array}{l}\text { Compound } \\
3\end{array}$ & $\begin{array}{l}\text { Compound } \\
4\end{array}$ \\
\hline \multirow{2}{*}{$\overline{\beta_{x x x}}$} & - & & & \\
\hline & 1012.2344 & 1212.5142 & 1313.4110 & -798.5761 \\
\hline $\mathrm{B}_{\mathrm{yyy}}$ & 3.9060 & 48.8168 & 22.5129 & 290.5284 \\
\hline $\mathrm{B}_{\mathrm{zzz}}$ & -6.6272 & -42.6795 & -49.8294 & -6.4796 \\
\hline$B_{x y y}$ & -60.4597 & 56.9283 & 17.4641 & -258.1509 \\
\hline $\mathrm{B}_{\mathrm{xxy}}$ & -43.2091 & -62.6788 & 104.8227 & 379.0807 \\
\hline $\mathrm{B}_{\mathrm{xxz}}$ & 50.7876 & -20.4071 & 24.1829 & 91.9778 \\
\hline $\mathrm{B}_{\mathrm{xzz}}$ & 30.1311 & 30.4645 & 23.3960 & 20.8076 \\
\hline $\mathrm{B}_{\mathrm{yzz}}$ & -0.2993 & 20.5109 & 41.3647 & -17.4063 \\
\hline$B_{\text {yyz }}$ & 9.4506 & -103.0877 & -33.1970 & 28.4489 \\
\hline $\mathrm{B}_{\mathrm{xyz}}$ & -18.9148 & 37.4798 & 33.4052 & -40.0521 \\
\hline \multicolumn{5}{|l|}{$\mathrm{B}_{0}(\mathrm{esu}) \times 10^{-}$} \\
\hline 33 & 1043.9808 & 1310.5023 & 1366.0061 & 1229.4232 \\
\hline$\mu_{\mathrm{x}}$ & -7.4387 & 8.7722 & 7.6038 & -6.0696 \\
\hline$\mu_{\mathrm{y}}$ & -0.5631 & -0.0425 & 0.5484 & 3.8389 \\
\hline$\mu_{\mathrm{z}}$ & 0.8396 & -2.6266 & -0.3713 & 1.0091 \\
\hline$\mu_{0}(\mathrm{D})$ & 7.5071 & 9.1571 & 7.6326 & 7.2523 \\
\hline$\alpha_{\mathrm{xx}}$ & -293.9163 & -321.9071 & -383.2769 & -299.5143 \\
\hline$\alpha_{\mathrm{yy}}$ & -183.0130 & -213.9923 & -270.8280 & -292.7141 \\
\hline$\alpha_{\mathrm{zz}}$ & -229.6318 & -242.1751 & -294.1025 & -305.5018 \\
\hline$\alpha_{\mathrm{xy}}$ & 4.9473 & -7.5556 & -14.4507 & 87.1779 \\
\hline$\alpha_{\mathrm{xz}}$ & 12.3004 & -8.0737 & -7.6089 & -1.1534 \\
\hline$\alpha_{\mathrm{yz}}$ & 3.0802 & -0.2419 & 1.3982 & -15.5910 \\
\hline$\alpha(\mathrm{esu}) \times 10^{-24}$ & 99.2898 & 98.8207 & 106.6550 & 153.8051 \\
\hline \multicolumn{5}{|l|}{$\Delta \alpha(\mathrm{esu}) \times 10^{-}$} \\
\hline 24 & 14.7147 & 14.6452 & 15.8063 & 22.7939 \\
\hline
\end{tabular}
sotropy of polarizability $(\Delta \alpha)$ and first hyperpolarizability $\left(\beta_{0}\right)$ for of (exTTF) derivatives molecules at B3LYP/6-31G $(\mathrm{d}, \mathrm{p})$ are listed in Table 10.

Table 10: The Dipole Moments $\mu 0$ (D), Polarizability $\alpha$, the Average Polarizability $\alpha$ (Esu), the Anisotropy of the Polarizability $\Delta \alpha$ (Esu), and the First Hyperpolarizability B0 (Esu) of (Exttf) Derivatives 1-4 Calculated by B3LYP/6-31G (D, P) Method

Since the values of the polarizabilities $(\Delta \alpha)$ and the hyperpolarizabilities $\left(\beta_{0}\right)$ of the GAUSSIAN 09 output are obtained in atomic units (a.u.), the calculated values have been converted into electrostatic units (e.s.u.) (for $\alpha ; 1$ a.u $=0.1482 \times 10^{-24}$ e.s.u., for $\beta ; 1$ a.u $=$ $8.6393 \times 10^{-33}$ e.s.u.). The calculated values of dipole moment $\left(\mu_{0}\right)$ for the title compounds were found to be 7.5071, 9.1571, 7.6326 and 7.2523 D respectively, which are approximately nine times than to the value for urea $(\mu=1.3732 \mathrm{D})$. Urea is one of the prototypical molecules used in the study of the NLO properties of molecular systems. Therefore, it has been used frequently as a threshold value for comparative purposes. The calculated values of polarizability are $99.2898 \times 10^{-24}, 98.8207 \times 10^{-24}, 106.6550 \times 10^{-24}$ and 153.8051 $\mathrm{x} 10^{-24}$ esu respectively; the values of anisotropy of the polarizability are $14.7147,14.6452,15.8063$ and 22.7939 esu, respectively. The magnitude of the molecular hyperpolarizability $\left(\beta_{0}\right)$ is one of important key factors in a NLO system. The DFT/6-31G (d,p) calculated first hyperpolarizability value $\left(\beta_{0}\right)$ of (exTTF) derivatives molecules are equal to $1043.9808 \times 10^{-33}, 1310.5023 \times 10^{-33}$, 
$1366.0061 \times 10^{-33}$ and $1229.4232 \times 10^{-33}$ esu. The first hyperpolarizability of title molecules is approximately $3.04,3.82,3.98$ and 3.58 times than those of urea ( $\beta$ of urea is $343.272 \times 10^{-33}$ esu obtained by B3LYP/6-311G (d,p) method). This result indicates the non-linearity of the (exTTF) derivatives 1-4.

\section{Conclusion}

We have carried out density functional theory calculations on the structure, hyperpolarizability and NBO, HOMO-LUMO, MEP analyses of (exTTF) derivatives 1-4 The equilibrium geometry by B3LYP/6-31G(d,p) level for the bond lengths, bond angles and dihedral angles is performed better.

The calculated HOMO and LUMO energies show that the charge transfer occurs within the molecules. The molecular stability and bond strength have been investigated by applying the natural bond orbital analysis. The first hyperpolarizability of the studied molecules indicates that the compounds are a good candidate for nonlinear optical materials. In addition, molecular electrostatic potential and frontier molecular orbital analysis were investigated using theoretical calculations.

\section{Acknowledgments}

This work was generously supported by the (General Directorate for Scientific Research and Technological Development, DGRSDT) and Algerian Ministry of Scientific Research.

\section{References}

[1] Giacalone F, Segura JL, Martín N, Guldi DM. (2004). Exceptionally small attenuation factors in molecular wires. J. Am. Chem. Soc. 126(17): 5340-5341. https://doi.org/10.1021/ja0318333.

[2] Lorcy D, Bellec N, Fourmigue M, Avarvari N. (2009). Tetrathiafulvalene-based group XV ligands: Synthesis, coordination chemistry and radical cation salts. Coord. Chem. Rev. 253(9-10): 1398-1438. https://doi.org/10.1016/j.ccr.2008.09.012.

[3] Khodorkovsky V, Becker JV. (1994). in organic conductors: Fundamentals and applications; Farges, J. P., Ed.; Marcel Dekker: New York, Chapter 3, 75. ISBN 9780824792169.

[4] Bryce MR. (1995). Current trends in tetrathiafulvalene chemistry: towards increased dimensionality. J. Mater. Chem. 5: 1481-1496. https://doi.org/10.1039/jm9950501481.

[5] Jen AK, Rao VP, Drost KJ, Wong KY, Cava MP. (1994). Optimization of thermal stability and second-order nonlinear optical properties of thiophene derived chromophores J. Chem. Soc. Chem. Commun. (18): 2057-2058. https://doi.org/10.1039/c39940002057.

[6] Brisset H, Thobie-Gautier C, Jubault M, Gorgues A, Roncali J. (1994). Small bandgap molecular semiconductors based on rigidified tetrathiafulvalene-bithiophene hybrid conjugated systems. J. Chem. Soc. Chem. Commun. (15): 1765-1766. https://doi.org/10.1039/C39940001765.

[7] Takahashi K, Tomitani K, Ise T, Shirahata T. (1995). Selenienoquinonoid-extended analogues of TTF, EDT-TTF and BEDT-TTF. New donors and their conductive complexes, Chem. Lett. 24(8): 619-620. https://doi.org/10.1246/cl.1995.619.

[8] Hohenberg P, Kohn W. (1964). Inhomogeneous electron gas. Phys. Rev. 136(3B): 864-870. https://doi.org/10.1103/PhysRev.136.B864.

[9] Kohn W. (1999). Electronic structure of matter-wave functions and density functionals. Rev. Mod. Phys. 71(5): 1253-1266. https://doi.org/10.1103/RevModPhys.71.1253.

[10] Kohn W., Sham LJ. (1965). Self-consistent equations including exchange and correlation effects. Phys. Rev. 140(4A): A1133. https://doi.org/10.1103/PhysRev.140.A1133.

[11] Otero M, Angeles HM, Seoane C, Martin N, Garin J, Orduna J, Alcala R, Villacampa B. (2002). Synthesis and properties of push-pull chromophores for second-order nonlinear optics derived from $p$-extended tetrathiafulvalenes (TTFs). Tetrahedron. 58 (37): 7463-7475. https://doi.org/10.1016/S0040-4020(02)00803-7.

[12] Frisch MJ, Trucks GW, Schlegel HB, Scuseria GE. (2009). Gaussian 09, Revision B. 01, Gaussian, Inc., Wallingford, CT.

[13] Becke AD. (1993). Density-functional thermochemistry. III. The role of exact exchange. J. Chem. Phys. 98(7): 5648-5652. https://doi.org/10.1063/1.464913.
[14] Lee CT, Yang WT, Parr RGB. (1988). Development of the collesalvetti correlation-energy formula into a functional of the electron density. Phys. Rev. 37(2): 785-789. https://doi.org/10.1103/PhysRevB.37.785.

[15] Petersson DA, Allaham MA. (1991). A complete basis set model chemistry. II. Open-shell systems and the total energies of the firstrow atoms. J. Chem. Phys. 94(9): 6081-6090. https://doi.org/10.1063/1.460447.

[16] Petersson GA, Bennett A, Tensfeldt TG, Allaham MA, Mantzaris WAJ, Shirley WA, (1988). A complete basis set model chemistry. I. The total energies of closed-shell atoms and hydrides of the first-row elements. J. Chem. Phys. 89(4): 2193-2218. https://doi.org/10.1063/1.455064.

[17] Scrocco E, Tomasi J. (1978). Electronic molecular structure. Advances in Quantum Chemistry, Academic Press, New York. 2: 115193.

[18] Murray JS, Sen K. (1996). Molecular electrostatic potentials, concepts and applications, 3, Elsevier, Amsterdam. ISBN: 9780080536859

[19] Curtiss LA, Redfern PC, Raghavachari K, Pople JA. (1998). Assessment of Gaussian-2 and density functional theories for the computation of ionization potentials and electron affinities J. Chem. Phys. 42(1): 117-122. https://doi.org/10.1063/1.476538.

[20] Hohenberg P, Kohn W. (1964). Inhomogeneous electron gas. phys. Rev. 136(3B): 864-870. https://doi.org/10.1103/PhysRev.136.B864.

[21] Srivastava A, Rawat P, Tandon P, Singh RN. (2012). A computational study on conformational geometries, chemical reactivity and inhibitor property of an alkaloid bicuculline with $\gamma$-aminobutyric acid (GABA) by DFT Comput. Theor. Chem. 993: 80-89. https://doi.org/10.1016/i.comptc.2012.05.025.

[22] Ayres PW, Parr RG. (2000). Variational principles for describing chemical reactions: The fukui function and chemical hardness revisited. J. Am. Chem. Soc. 122(9): 2010-2018 https://doi.org/10.1021/ja9924039.

[23] Parthasarathi R, Padmanabhan J, Subramanian V, Maiti B, Chattaraj PK. (2003). Chemical reactivity profiles of two selected polychlorinated biphenyls. J. Phys. Chem. A 107(48): 10346-10352. https://doi.org/10.1021/jp035620b.

[24] Reed AE, Curtiss LA, Weinhold F. (1988). Intermolecular interactions from a natural bond orbital, donor-acceptor viewpoint. Chem Rev. 88(6): 899-926. https://doi.org/10.1021/cr00088a005.

[25] Foster JP, Weinhold F. (1980). Natural hybrid orbitals. J. Am. Chem. Soc. 102(24): 7211-7218. https://doi.org/10.1021/ja00544a007.

[26] Weinhold F, Landis CR. (2005). Valency and Bonding: A natural bond orbital donor-acceptor perspective, Cambridge University

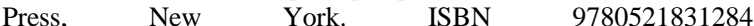
https://doi.org/10.1017/CBO9780511614569.

[27] Ravikumar C, Padmaja L, Hubert Joe I. (2008). Analysis of vibrational spectra of L-Alanyl glyciene based on density functional theory calculations. Spectrochimica. Acta Part A. 71(1): 252-262. https://doi.org/10.1016/j.saa.2007.12.019.

[28] Arul Dhas D, Hubert Joe I, Roy SDD, Freeda TH. (2010). DFT computations and spectroscopic analysis of a pesticide: Chlorothalonil. Spectrochimica. Acta. Part A. 77(1): 36-44 https://doi.org/10.1016/j.saa.2010.04.020.

[29] Sun Y, Chen X, Sun L, Guo X, Lu W. (2003). Nanoring structure and optical properties of Ga8As8. Chem. Phys. Lett. 381(3-4): $397-$ 403. https://doi.org/10.1016/j.cplett.2003.09.115.

[30] Hald K, Pawłowski F, Jørgensen P. (2003). Calculation of frequency-dependent polarizabilities using the approximate coupledcluster triples model CC3. The Journal of Chemical Physics. 118(3) 1292-1300. https://doi.org/10.1063/1.1523905.

[31] Kleinmann DA. (1962). Nonlinear dielectric polarization in optical media. Phys. 126(6): Rev. 1977-1979. https://doi.org/10.1103/PhysRev.126.1977. 